J. Lake Sci. (湖泊科学) , 2012, 24(1): 89-95

http: //www. jlakes. org. E-mail : jlakes@niglas.ac.cn

(c) 2012 by Journal of Lake Sciences

\title{
巢湖典型子流域上下游水塘对暴雨径流氮磷去除效率比较”
}

\author{
聂小飞 ${ }^{1,2}$, 李恒鹏 ${ }^{1 * *}$, , 李新艳 $^{1}$ \\ ( 1 :中国科学院南京地理与湖泊研究所湖泊与环境国家重点实验室,南京 210008) \\ (2: 中国科学院研究生院, 北京 100049$)$
}

摘 要: 从流域上下游环境条件及氮磷输出强度差异出发, 探讨上下游水塘对径流氮磷去除的特征及效率, 选取巢湖小 柘臬河源头流域上下游水塘开展水塘去除暴雨径流氮磷的对比试验, 研究暴雨及暴雨间期上下游水塘氮磷去除效率差 异及原因, 为流域上下游设计不同类型净化塘去除氮磷提供科学依据. 结果表明: 暴雨期, 上游径流氮磷浓度高于下游, 且颗粒态所占比例上游大于下游, 流域上游应作为防治暴雨径流氮磷流失的重点区域; 暴雨期, 上游塘对暴雨径流中的 氮磷去除效果明显,氮、磷去除率分别为 $74 \%$ 和 $52 \%$, 且对颗粒态去除效果好于溶解态, 下游塘没有表现出明显的去除效 果; 暴雨间期, 上游塘塘内氮磷浓度平均下降 50\% 和 $20 \%$, 下游塘则分别为 $72 \%$ 和 $16 \%$, 且均以溶解态去除为主; 水塘去 除暴雨径流氮磷有一定的浓度适用范围, 浓度过低, 去除效果不明显; 流域部位不同引起人塘径流氮磷浓度和形态的差 异是上下游水塘对暴雨径流去除效果差异的主要外部原因. 流域上游出山口, 可以在渗透性好的山前洪积扇上构建深水 宽塘, 通过增加暴雨径流拦截量和降低流速增强物理沉降作用, 实现暴雨径流氮磷的高效去除; 流域下游农田区, 宜构建 水面较大的浅滩湿地,通过延长滞留时间和促进生物活动增强去除暴雨径流氮磷的效果.

关键词: 巢湖典型子流域;暴雨径流;水塘;氮;磷;去除效率

\section{Comparison of nitrogen and phosphorus removal efficiencies by storm runoffs for the ponds in the upper and lower reaches of a typical sub-catchment in Lake Chaohu drain- age basin}

\author{
NIE Xiaofei ${ }^{1,2}$, LI Hengpeng ${ }^{1} \&$ LI Xinyan ${ }^{1}$ \\ ( 1 : State Key Laboratory of Lake Science and Environment, Nanjing Institute of Geography and Limnology, Chinese Academy \\ of Sciences, Nanjing 210008, P. R. China) \\ (2: Graduate University of Chinese Academy of Sciences, Beijing 100049, P. R. China)
}

\begin{abstract}
In this paper, we analyze the removal efficiencies and characteristics of nitrogen and phosphorus in storm runoff in two ponds located in the upper and lower reaches of Xiaozhegao Stream, Lake Chaohu drainage basin. Results indicate that in the storm period, the runoff nitrogen and phosphorus levels in the upper reaches of stream are higher than those in the lower reaches. There is a good removal performance for the upper pond on both nitrogen and phosphorus (mainly in particulate), with a removal efficiency of $74 \%$ and $52 \%$, respectively, while no evident removal performance has been found in the lower pond. During non-storm period, both ponds have good removal performances for dissolved nutrients. In the upper pond, the removal rates are $50 \%$ and $20 \%$ for nitrogen and phosphorus, respectively; in the lower pond, the rates are $72 \%$ and $16 \%$ for nitrogen and phosphorus, respectively. There is a range of nutrient concentration that ponds could play a good removal performance: if the nutrient concentration is too low, there will be no evident nutrient removal. The two ponds have different removal efficiencies on runoff nutrients due to their different locations in the catchment. The study concludes that in the upper reaches of a catchment, which is the most important area to prevent and control the loss of nutrients from storm runoff, ponds should be constructed deep and wide in the front of alluvial fan.
\end{abstract}

* 国家水体污染控制与治理科技重大专项项目(2008ZX07103-003)、国家自然科学基金项目(40871238)和江苏省自 然科学基金项目 (BK2009335) 联合资助. 2011-03-21 收稿;2011-05-23 收修改稿. 聂小飞,男, 1985 年生,博士 研究生;E-mail:niexiaofei222@yahoo. com.cn.

** 通信作者;E-mail:hpli@ niglas. ac. cn. 
It will enhance the physical settlement of nutrients by intercepting the runoff and lowering the flow velocity. While in the lower reaches of a catchment, it is appropriate to construct big and shallow wetlands which will remove much nitrogen and phosphorus in storm runoff by delaying nutrient retention time and promoting biological activity. The research could benefit better design of the ponds which aims to control water eutrophication.

Keywords: Lake Chaohu drainage basin; storm runoff; pond; nitrogen; phosphorus; removal efficiency

巢湖富营养化问题非常突出, 是我国重点治理的湖泊之一 ${ }^{[1]}$. 湖泊富营养化与流域氮磷污染密切相关, 已有研究显示, 随着点源污染得到逐步控制, 面源氮磷污染已经成为湖泊氮磷的主要来源, 削减流域面源氮 磷污染成为治理湖泊富营养化的关键 ${ }^{[2-3]}$. 然而, 面源污染因空间分布广泛, 难以集中处理, 目前主要通过塘 库湿地加以去除 ${ }^{[4-9]}$, 如美国 TMDL 计划把塘库湿地技术作为削减面源污染, 改善受损水体水质的重要手 段 ${ }^{[10]}$. 目前国内外针对自然和人工塘库湿地开展了大量的研究, 主要通过实测方法研究塘库系统对氮、磷的 去除效率及其与塘库特征参数的定量关系, 为设计氮磷去除的塘库系统提供科学依据. 相关学者的研究结 果显示, 水塘对氮磷的去除效果与众多因素有关,包括人塘径流氮磷浓度、在水塘滞留的时间、水体的流态、 水塘的水生植被条件、底泥吸附容量等 ${ }^{[4,11-17]}$. 国内一些学者在巢湖和太湖开展了试验研究,证实自然水塘 系统对暴雨径流氮磷具有较强的去除能力, 并计算了典型塘库对氮磷的去除效率 ${ }^{[5,16-20]}$. 由于塘库系统对氮 磷去除涉及沉降、吸附、硝化、反硝化、氨挥发以及生物吸收等众多物理、化学、生物过程, 而且影响因素众 多 ${ }^{[4,7]}$, 至今尚缺乏严格的数学描述, 实际应用中仍以相应地区的试验结果作为重要依据. 本研究重点针对 巢湖临湖地区的面源氮磷污染问题, 从流域角度出发, 考虑到上下游水力条件差异、径流氮磷浓度及不同形 态氮磷组成结构的差异, 选择小流域上下游两种典型的水塘开展氮磷去除特征及效率的比较研究, 为流域 尺度的面源氮磷去除以及在流域上下游差别化设计合理的氮磷去除塘库类型提供科学依据.

\section{1 研究区与研究方法}

\section{1 试验流域自然条件}

试验区位于巢湖东北岸小柘臬河源头小流域, 距湖岸约 $4 \mathrm{~km}$ (图 1), 属于低山丘陵地区, 北亚热带湿润 季风气候,多年平均降水量为 $1120 \mathrm{~mm}$, 降水最集中的 5-8 月份降水量占全年的 $53.2 \%, 2010$ 年 5-8 月降 雨日平均雨强为 $10.7 \mathrm{~mm} / \mathrm{d}$, 最大雨强为 $53.4 \mathrm{~mm} / \mathrm{d}^{\mathbb{1}}$. 所在小流域土地利用以林地、草地、水田为主, 流域

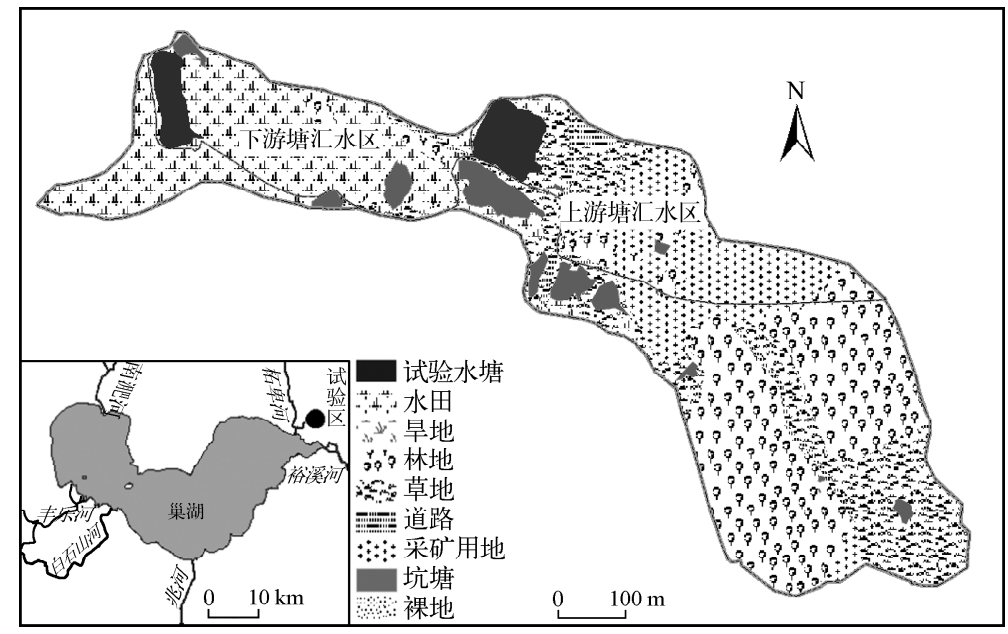

图 1 水塘系统分布图

Fig. 1 Location of ponds in the catchment

(1) 巢湖多年平均降水数据基于巢湖气象站(国家级, 编号 58326)1961-2010 年 50 年的日降水数据统计得到, 2010 年降水数据基于当年日降水数据统计得到. 
上游山体因采矿活动分布有较大的裸露面. 2010 年 7 月,林地盖度约 70\%, 草地 $95 \%$ 左右, 水田盖度逐渐增 大, 平均约为 $75 \%$ (图 1).

试验水塘位于上游出山口(下称“上游塘”) 和下游农田区(下称“下游塘”), 分别处于洪积扇上和洪积 扇前缘 (图 1). 上游塘面积为 $0.74 \mathrm{hm}^{2}, 2009$ 年冬季平均实测水深 $1.15 \mathrm{~m}$, 采样期间最大水位差为 $0.76 \mathrm{~m}$, 塘内无水草分布; 下游塘 $0.49 \mathrm{hm}^{2}$, 平均实测水深 $1.60 \mathrm{~m}$, 采样期间最大水位差为 $0.31 \mathrm{~m}$, 塘内水草较多, 以 菱角和空心莲子菜为主, 盖度约 $25 \%$ (2010 年 7 月).

\section{2 监测与分析方法}

考虑到暴雨期间水塘对径流氮磷的削减以物理过程为主, 而非降雨期与化学及生物过程更为相关, 本 研究选择典型暴雨期及暴雨间期开展监测. 暴雨主要指研究区内有明显地表径流并能够补给水塘的降雨过 程, 暴雨间期界定在气象观测的暴雨事件降水过程结束后 $24 \mathrm{~h}$ 至下一次暴雨开始前夕. 采样期间降水数据 采用同步记录的巢湖气象站实测数据.

在降水最集中、强度最大的 7、8 月选取 2 次典型暴雨事件对试验水塘进行暴雨过程 (即雨中阶段) 采 样, 分析水塘对暴雨径流氮磷的拦截效果; 在暴雨间期 (即雨后一雨前阶段) 采样, 了解塘内水体氮磷的净化 情况. 其中 2010 年 7 月暴雨过程, 历时 $41 \mathrm{~h}$, 累计降水 $67.8 \mathrm{~mm}$;2010 年 8 月暴雨过程, 历时 $24 \mathrm{~h}$, 累计降水 $51.3 \mathrm{~mm} .7$ 月暴雨累计采样 6 次, 其中雨中 4 次,雨前、雨后各 1 次; 8 月暴雨累计采样 3 次, 其中雨中 1 次; 雨前、雨后各 1 次. 暴雨期, 在水塘的人水口和出水口采集水样; 暴雨间期,仅在水塘中间部位采样. 降水结 束 $24 \mathrm{~h}$ 后, 研究区内地表径流基本消失,采集塘内水样检测初始浓度; 王沛芳等在太湖地区水塘系统的研究 表明, 雨后塘中的营养元素浓度随时间不断降低, 最终逐渐趋于稳定 ${ }^{[19]}$, 本研究 2 次暴雨前无有效降雨时间 均超过 $10 \mathrm{~d}$,故可在暴雨前夕采集塘内水样检测稳定浓度.

本研究 2.1.2 和 2.2.1 中所用数据为 7 月份和 8 月份两场暴雨的 5 次雨中采样数据的平均值, 2.3 中所 用数据为雨前、雨后各 2 次采样数据的平均值, 2.2.2 中分析人塘径流浓度对去除效果的影响时, 采用的是 两场暴雨 5 次雨中采样数据的原始值, 2.2.3 中分析不同雨强条件下去除效果的差异时,采用的是上游塘 7 月份暴雨 4 次雨中连续采样数据的原始值.

采集的水样分析前于 $4^{\circ} \mathrm{C}$ 冷藏保存, 并尽快送往实验室进行水化分析, 检测总氮 (TN)、总磷 (TP)、溶解 态氮 (DTN) 、溶解态磷 (DTP). TN 、TP 采用碱性过硫酸钾高温消解后紫外分光光度法和钼酸铵分光光度法 测定 ${ }^{[21]}$; DTN、DTP 则采用 Whatman GF/C 膜过滤后的水样加碱性过硫酸钾高温消解, 其余步骤同 TN、TP 的 测定, 方法检测限为 $0.01 \mathrm{mg} / \mathrm{L}$. 颗粒态氮 $(\mathrm{PN})$ 、颗粒态磷 $(\mathrm{PP})$ 分别为 TN 与 DTN、TP 与 DTP 的差值.

\section{3 氮磷去除率的评价方法}

不同水塘初始水位差异 (受前期用水影响, 如灌溉) 、容量差异均会影响到水塘对 N、P 去除量的计算, 为 了便于比较上下游水塘对 $\mathrm{N} 、 \mathrm{P}$ 去除率差异, 本研究采用浓度指标变化来评价水塘的去除率. 具体计算方 法为:

$$
\begin{aligned}
& \text { 暴雨期间: } P e r_{\text {Concentration Removal }}=\left(1-C_{\text {Outlet }} / C_{\text {Inlet }}\right) \times 100 \% \\
& \text { 暴雨间期: } P e r_{\text {Concentration Removal }}=\left(1-C_{\text {final }} / C_{\text {orignal }}\right) \times 100 \%
\end{aligned}
$$

式中, $P e r_{\text {Concentration Removal }}$ 为去除率 (暴雨期为拦截率, 暴雨间期为净化率), $C_{\text {Inlet } ~} C_{\text {Outlet }}$ 分别为暴雨期水塘水体的 输人、输出浓度, $C_{\text {original }} 、 C_{\text {final }}$ 分别为暴雨间期塘内水体的初始、稳定浓度.

\section{2 结果与分析}

\section{1 流域上下游环境条件及径流营养盐输出特征比较}

2.1.1 上下游水塘汇水区土地利用与地形差异 上游塘位于出山口洪积扇上, 下游塘则在洪积扇前的农田 区,所处流域部位的不同使它们表现出完全不同的土地利用结构.上、下游水塘汇水区面积分别为 6.15 、 $5.57 \mathrm{hm}^{2}$. 上游塘汇水区以裸地 (开矿导致的裸露、破碎山体)、草地、林地为主, 分别占相应汇水区面积的 $52.2 \% 、 21.5 \%$ 和 $17.0 \%$; 下游塘则以耕地为主, 水田和旱地的比例分别达到了 $55.9 \%$ 和 $27.4 \%$ (图 2).

流域部位不同引起的差异还体现在汇水区平均坡度和沟渠的比降 (沟渠高程差/沟渠长) 上. 上游塘汇 

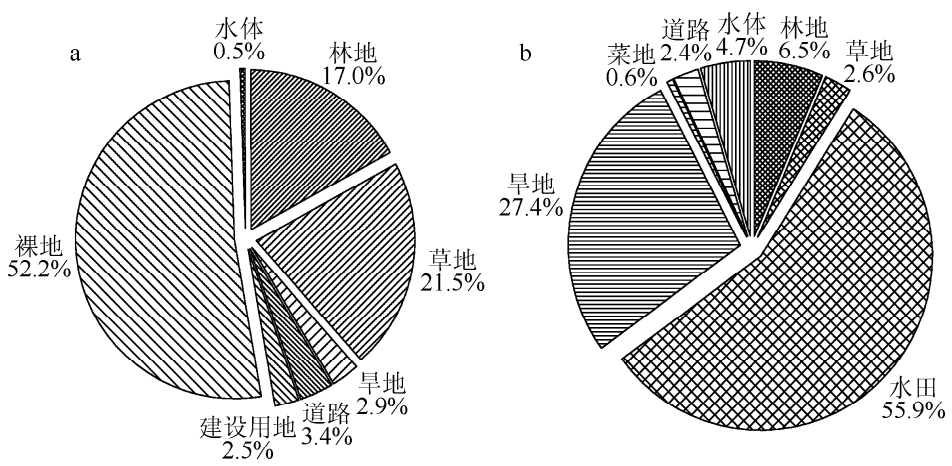

图 2 上游塘汇水区 ( a ) 和下游塘汇水区 (b) 土地利用结构

Fig. 2 Landuse structure of catchment for upper pond (a) and lower pond (b)

水区平均坡度为 $15^{\circ}$, 而下游塘汇水区平均坡度只有 $9^{\circ}$. 沟渠的比降也表现出巨大的差异, 上游塘沟渠比降 高达 0.19 , 而下游塘仅为 0.02 .

2.1 .2 上下游水塘入塘径流氮磷浓度差异 上下游水塘汇水区下垫面条件、水力特性等环境条件的差异, 导 致上下游汇水区的产汇流过程存在明显的差异, 并影响到上下游人塘径流的 $\mathrm{N} 、 \mathrm{P}$ 浓度及形态组成. 就 $\mathrm{N}$ 而 言, 暴雨期, 上游塘的 TN、DTN 和 PN 浓度均明显高于下游塘; 从形态组成来看, 上下游水塘来水中 $\mathrm{N}$ 均以溶 解态为主. P 的特征与 $\mathrm{N}$ 具有一定的差异, 上游人塘径流 TP、PP 浓度均高于下游塘, 但 DTP 浓度略低于下游 塘, 表明上游塘来水 $\mathrm{TP}$ 浓度较高主要是 $\mathrm{PP}$ 含量增加导致. 总体来说, 上游塘来水中 $\mathrm{P}$ 以颗粒态为主, 占

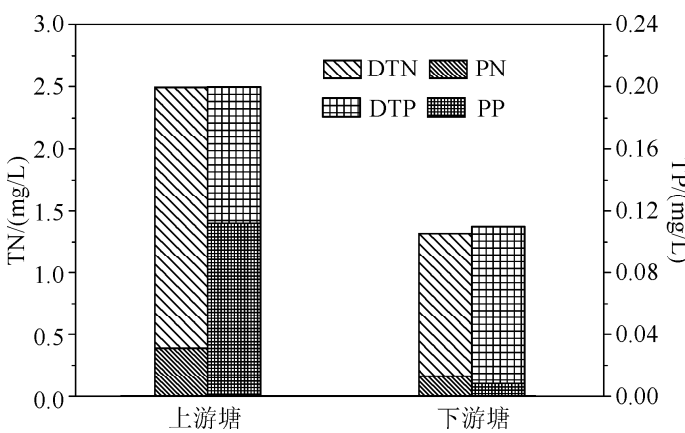

图 3 上、下游水塘人塘暴雨径流氮、磷浓度

Fig. 3 Concentrations of nitrogen and phosphorus input to the upper and lower ponds
$56 \%$;下游塘以溶解态为主, 高达 $93 \%$.

上下游水塘来水 $\mathrm{N} 、 \mathrm{P}$ 浓度及形态组成规律也不 一致(图 3 ). 上游塘来水 $\mathrm{TN} 、 \mathrm{DTN} 、 \mathrm{PN} 、 \mathrm{TP}$ 和 PP 浓度 均高于下游塘来水 (表 1 ), 且来水中 $\mathrm{N}$ 均以溶解态为 主, 但上游塘来水 $\mathrm{PN} 、 \mathrm{PP}$ 的比例较下游高, 且 $\mathrm{P}$ 的差 异比 $\mathrm{N}$ 表现得更为明显.

\section{2 上下游水塘在暴雨过程对氮磷的去除率差异}

2.2.1 上下游水塘对暴雨径流中氮磷的拦截效果暴 雨期间, 上游塘对径流氮磷拦截效果明显好于下游 塘. 上游塘对人塘径流 TN 的去除率达到 74\%, 其中 DTN 、PN 的去除率分别为 $78 \% 、 51 \%$; 上游塘对 TP 的 去除率为 $52 \%$, 其中 DTP、PP 的去除率分别为 $13 \%$ 、 $83 \%$. 而下游塘对人塘暴雨径流 N、P 拦截效果不明显 (表 1). 从形态来看, 上游塘对人塘径流中 PN、PP 均 表现出较好的去除效果, 表明暴雨期间, 水塘对暴雨径流的去除作用主要由位于流域上游的水塘发挥, 且水 塘对颗粒态的去除效果好于溶解态.

表 1 上、下游水塘对人塘暴雨径流 $\mathrm{N} 、 \mathrm{P}$ 的去除率 *

Tab. 1 Removal efficiencies of nitrogen and phosphorus in storm runoff for the upper and lower ponds

\begin{tabular}{llcccccc}
\hline 水塘 & 类别 & $\mathrm{TN}$ & $\mathrm{PN}$ & $\mathrm{DTN}$ & $\mathrm{TP}$ & $\mathrm{PP}$ & $\mathrm{DTP}$ \\
\hline 上游塘 & 人塘浓度 $/(\mathrm{mg} / \mathrm{L})$ & $2.49 \pm 1.58$ & $0.39 \pm 0.14$ & $2.10 \pm 1.53$ & $0.20 \pm 0.07$ & $0.11 \pm 0.07$ & $0.09 \pm 0.01$ \\
& 下去除率 $/ \%$ & 74 & 51 & 78 & 52 & 83 & 13 \\
下游塘 & 人塘浓度 $/(\mathrm{mg} / \mathrm{L})$ & $1.32 \pm 0.43$ & $0.16 \pm 0.10$ & $1.16 \pm 0.049$ & $0.11 \pm 0.01$ & $0.01 \pm 0.01$ & $0.10 \pm 0.02$ \\
& 去除率 $/ \%$ & 2 & 21 & - & - & - & 2 \\
\hline
\end{tabular}


2.2.2 入塘暴雨径流浓度对去除效果的影响 水塘去除暴雨径流中 TN 、 $\mathrm{TP}$ 的效果, 与人塘径流 $\mathrm{TN} 、 \mathrm{TP}$ 浓度 呈显著正相关, 其中 $\mathrm{TN}$ 的 $r=0.66, n=10, P=0.038$, TP 的 $r=0.92, n=10, P<0.001$. 随人塘径流浓度的降 低, 水塘对 TN、TP 的去除率呈现下降趋势. 当人塘径流 TN、TP 浓度过低, 小于特定阈值时, 水塘对暴雨径流 中 TN 、TP 无明显去除效果. 相应地, 人塘径流 TN、TP 浓度过高时, 即使浓度去除率高达 $90 \%$ 以上, 出水浓度 依然较高. 因此, 应用自然水塘防治面源氮磷污染时, 需要注意其适用浓度范围, 否则可能达不到预期的处 理效果. 试验中, 下游水塘对浓度过低的 DTN、TP、PP 没有明显的去除效果便是实例.

2.2 .3 不同雨强条件下去除效果的差异 暴雨期, 研究区域氮磷去除以上游水塘为主, 本研究选择流 域上游部位的水塘, 分析不同雨强条件下去除效果 的差异. 由 TN、TP 去除率与雨强之间的关系可知: 不同雨强条件下水塘对人塘径流中 TP 的去除效果 差异明显 (图 4). 雨强越大, 水塘对人塘径流中 TP 的去除率越高, 降水后期, 雨强减小时, 水塘对人塘 径流中 TP 的去除率显著降低. 水塘对人塘径流中 TN 的去除效果除了受雨强的影响, 还与降水过程 有关: 随着降水过程的推进, 水塘对人塘径流中 $\mathrm{TN}$ 的去除率呈增大趋势, 即使降水后期雨强显著减 小, 水塘对人塘径流中 $\mathrm{TN}$ 的去除率仍有所提高, 这 与人塘径流中 $\mathrm{TN}$ 的浓度在降雨后期有所升高 有关.

\section{3 上下游水塘在暴雨间期对氮磷的去除率差异}

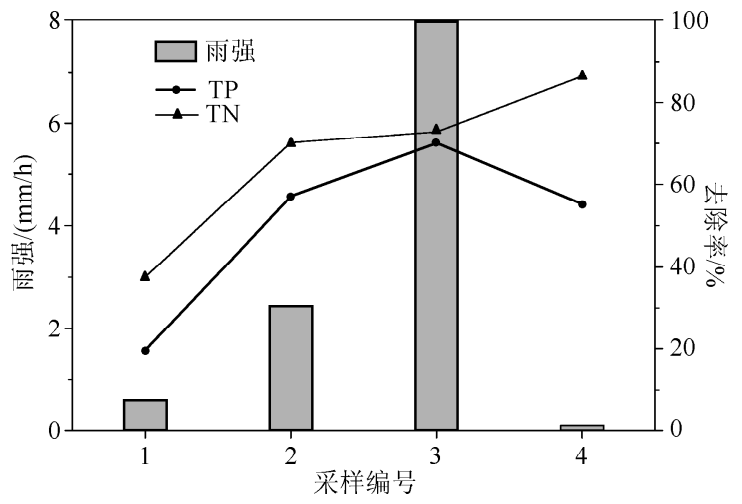

图 4 不同雨强条件下水塘对人塘暴雨径流 $\mathrm{TN} 、 \mathrm{TP}$ 的去除效果

Fig. 4 Removal efficiencies of nitrogen and phosphorus in storm runoff under different rainfall intensities

暴雨间期,上、下游塘对塘内水体氮有明显的去除效果. 下游塘对塘内水体 $\mathrm{TN}$ 的去除率达到 $72 \%$,好于 上游塘的 $50 \%$. 王沛芳等 ${ }^{[19]}$ 在太湖流域小坑塘的研究发现,7 月份坑塘对塘内水体 TN 雨后 7 天累计去除率 达 70.0\% 以上, 与本研究中下游塘对 $\mathrm{TN}$ 的去除率相当. 暴雨间期, $\mathrm{N}$ 的去除以溶解态为主, 上、下游塘对 DTN 的去除率分别达到了 $59 \%$ 和 74\%.上下游水塘对磷也有一定的去除效果, 且也以去除溶解态为主, DTP 去除率 分别达到了 $18 \%$ 和 $24 \%$ (表 2).

表 2 上下游水塘对塘内水体 $\mathrm{N} 、 \mathrm{P}$ 的净化作用

Tab. 2 Removal efficiencies of nitrogen and phosphorus in the upper and lower ponds

\begin{tabular}{rlcccccc}
\hline 水塘 & \multicolumn{1}{c}{ 类别 } & TN & PN & DTN & TP & PP & DTP \\
\hline 上游塘 & 初始浓度 $/(\mathrm{mg} / \mathrm{L})$ & $0.79 \pm 0.19$ & $0.16 \pm 0.03$ & $0.63 \pm 0.22$ & $0.08 \pm 0.03$ & $0.02 \pm 0.01$ & $0.06 \pm 0.03$ \\
& 去除率 $/ \%$ & 50 & - & 59 & 20 & 34 & 18 \\
下游塘 & 初始浓度 $/(\mathrm{mg} / \mathrm{L})$ & $1.08 \pm 0.63$ & $0.04 \pm 0.03$ & $1.03 \pm 0.06$ & $0.09 \pm 0.04$ & $0.02 \pm 0.01$ & $0.07 \pm 0.04$ \\
& 去除率 $/ \%$ & 72 & - & 74 & 16 & - & 24 \\
\hline
\end{tabular}

暴雨间期,水塘通过生物吸收、硝化、反硝化、氨挥发等作用为主去除水体中的溶解态营养盐. 尽管上、 下游水塘水面面积相当, 但下游塘内生长有大量的水生植被, 水草自身的吸收利用及其对氮循环微生物活 动的促进, 从而使得暴雨间期下游塘比上游塘对塘内水体中 DTN、DTP 具有更好的去除效果. 暴雨间期, PN、 PP 浓度极低,物理沉降、化学吸附作用极小, 因而暴雨间期,水塘对塘内 PN、PP 无明显的去除作用.

\section{3 讨论}

流域土地利用状况、坡度、沟渠的比降显著影响流域的产汇流情况及氮磷的输出强度. 地表裸露越多、 坡度越大,产汇流越迅速,地表径流流速越快、流量越大, 对地表的冲刷作用越强,氮磷流失越严重, 径流中 氮磷浓度越高, 颗粒态比重也越大. 流域上游区域平均坡度大、沟渠比降大, 地表一旦遭到人类活动的破坏 
(如采矿等) 出现裸露, 暴雨过程中产流迅速, 地表径流量增加, 流速快, 冲刷显著增强, 氮、磷携带量大, 且包 含大量的颗粒态氮磷. 流域下游区域地势平缓, 土地利用以耕地为主, 暴雨过程中产流较慢, 持续时间较长, 流速较缓, 地表冲刷强度较弱, 径流中氮磷以溶解态为主, 表现出以农田氮磷流失为主的特征. 针对上下游 区域暴雨过程氮磷流失特征, 控制暴雨期间氮磷流失尤为重要, 且应将坡面生态恢复与净化塘技术结合实 施, 另外针对暴雨径流氮磷的去除应以改变流态,最大强度地发挥物理去除作用为主.

水塘对暴雨径流中氮磷的去除在暴雨期和暴雨间期均有体现. 暴雨期, 水塘对暴雨径流中氮磷以拦蓄、 沉降等物理过程为主. 雨量较小, 径流相对较少时, 水塘通过调蓄容量拦蓄全部径流; 雨量较大, 径流较多 时, 水塘的调蓄容量也能够拦蓄前期高浓度的径流, 对暴雨径流中的氮磷具有显著的截留效应. 过量的径流 通过水塘时, 水面展宽, 流速变缓, 水体携带悬浮物的能力显著降低, 大量的颗粒态氮磷随附着的悬浮物沉 降下来, 同时, 塘内水体的稀释、底泥吸附等作用, 也使得出塘径流氮磷浓度明显降低, 使得水塘对入塘径流 中的氮磷, 特别是颗粒态氮磷表现出良好的去除效果. 上游塘处于地势转折地带, 汇水区坡度大, 人塘径流 流速快, 氮磷浓度高, 颗粒态比例也相对较高, 径流人塘后, 水面展宽, 流速急剧减慢, 携带悬浮物的能力下 降, 径流中颗粒态氮磷浓度随悬浮物大量沉降; 下游塘处于地势平缓地带, 一方面径流经上游塘后, 颗粒态 氮磷浓度显著降低, 另一方面汇水区坡度缓, 径流流速慢, 人塘后流速变化不大, 沉降作用不明显, 因而暴雨 期上游塘表现出良好的去除效果, 且以颗粒态为主, 而下游塘暴雨期无明显的去除效果. 暴雨间期水塘对人 塘暴雨径流中氮磷的去除主要体现在存量净化上, 在进一步吸附与沉降的基础上, 以硝化/反硝化、氨挥发、 生物吸收等化学与生物过程为主, 尤其对溶解态氮磷去除作用明显. 生物、化学降解与水面大小和生物作用 均密切相关, 下游塘水草较多, 微环境更有利于硝化、反硝化、氨挥发、生物吸收等化学与生物过程的发生, 而上游塘无水草分布,因此暴雨间期下游塘去除效果更为明显.

从以上分析可以看出, 流域上游出山口径流流速快、冲刷能力强, 氮磷浓度高, 且径流携带的颗粒态氮 磷较多, 可以在渗透性好的山前洪积扇上构建深水塘, 增加蓄水量, 且水塘垂直于人塘沟渠处的宽度尽可能 大, 这样可以展宽水面, 减缓流速, 加快沉降与吸附. 流域下游农田区, 降雨产生的径流流速慢, 溶解态氮磷 流失更为突出, 可以构建水面较大的浅滩湿地, 延长出流路径, 减慢流速, 增加水体滞留时间, 通过生物吸 收、吸附、氨挥发、硝化/反硝化作用高效净化过塘径流.

致谢: 中国科学院南京地理与湖泊研究所王晓龙老师在试验设计、文章构思方面提出了宝贵建议; 刘焕金、 常龙飞、金黎明、韩堂、刘一兰等在样品采集和分析过程中提供了热心帮助,在此表示感谢!

\section{4 参考文献}

［1］殷福才, 张之源. 巢湖富营养化研究进展. 湖泊科学, 2003, 15(4) : 377-384.

[2] 金相灿, 刘树坤, 章宗涉等. 中国湖泊环境: 第 2 卷. 北京: 海洋出版社, 1995: 150-197.

[3] 李如忠, 汪家权, 钱如忠. 巢湖流域非点源营养物控制对策研究. 水土保持学报, 2004, 18(1): 119-121, 129.

[ 4 ] Kelly AC, Timothy JL, Emilie KS. Opportunities and challenges for managing nitrogen in urban stormwater: A review and synthesis. Ecological Engineering, 2010, 36: 1507-1519.

[ 5] 尹澄清, 单宝庆. 多水塘系统: 控制面源磷污染的可持续方法. AMBIO-人类环境杂志, 2001, 30(6): 369-375.

[6] 尹澄清, 毛战坡. 用生态工程技术控制农村非点源水污染. 应用生态学报, 2002, 13(2): 229-232.

[ 7 ] 涂安国, 尹 炜, 陈德强. 多水塘系统调控农业非点源污染研究综述. 人民长江, 2009, 40(21): 71-73.

[8] Shan Baoqing, Yin Chengqing, Li Guibao. Transport and retention of phosphorus pollutants in the landscape with a traditional, multi-pond system. Water Air and Soil Pollution, 2002, 139: 15-34.

[ 9 ] Yin CQ, Zhao M, Jin WG. A multi-pond system as a protective zone for the management of lakes in China. Hydrobiologia, 1993, 251 : 321-329.

[10 ] US EPA. Handbook for developing watershed TMDLs. Washington, DC: US Environmental Protection Agency, Office of Water, Office of Wetlands, Oceans and Watersheds, 2008: 81-87.

[11] Schueler TR. Review of pollution removal performance of stormwater ponds and wetlands. Watershed Protection Techniques, $1994,1(1): 17-18$.

[12] Thomas L. Stormwater quantity and quality in a multiple pond-wetland system: Flemingsbergsviken case study. Ecological 
Engineering, 2000, 15: 57-75.

[13] Fisher J, Acreman MC. Wetland nutrient removal: a review of the evidence. Hydrology and Earth System Sciences, 2004, 8(4): $673-685$.

[14] 陈庆锋, 单宝庆, 马君健等. 塘和湿地技术在面源污染控制中的应用组合模式探讨. 湿地科学与管理, 2008, 4 (4) : 36-39.

[15] 付 强, 尹澄清, 马 允. 源头农业区不同类型水塘中水体沉积物磷吸附容量. 环境科学, 2005, 26(4): 70-76.

［16］姜翠玲，崔广柏. 湿地对农业非点源污染的去除效应. 农村环境保护, 2002, 21(5)：471-473, 476.

[17] 毛战坡, 彭文启, 尹澄清等. 非点源污染物在多水塘系统中的损失特征研究. 农业环境科学学报, 2004, 23(3): 530-535.

[18] 毛战坡, 尹澄清, 单保庆等. 农业非点源污染物在水塘景观系统中的空间变异性研究. 水利学报, 2006, 37(6)： 727-739.

[19] 王沛芳, 王 超, 徐海波. 自然水塘湿地系统对农业非点源氮的净化截留效应研究. 农业环境科学学报, 2006, 25 (3) : 782-785.

[20] 孙庆业, 马秀玲, 阳贵德等. 巢湖周围池塘氮、磷和有机质研究. 环境科学, 2010, 31(7): 1510-1515.

[21] 金相灿, 屠清瑛. 湖泊富营养化调查规范: 第 2 版. 北京: 中国环境科学出版社, 1990: 138-206. 